This Section of Epidemiology and Psychiatric Sciences appears in each issue of the Journal and is dedicated to all forms of creative production born of an intimate and individual urge, often secretive, unbound from the conventional art system rules. Through short descriptions of the Outsider art work of prominent artists and new protagonists often hosted in community mental health services, this section intends to investigate the latest developments of the contemporary art scene, where the distances between the edge and the center are becoming more and more vague.

Carole Tansella, Section Editor

\title{
Courttney Cooper: mapping the interior
}

\section{Wiley}

Department of Outsider Art, The Center for Intuitive and Outsider Art, Chicago, Illinois, USA

Received 30 March 2017; Accepted 13 April 2017; First published online 18 May 2017

Keywords: Art, utsider art, ntuitive art, utism.

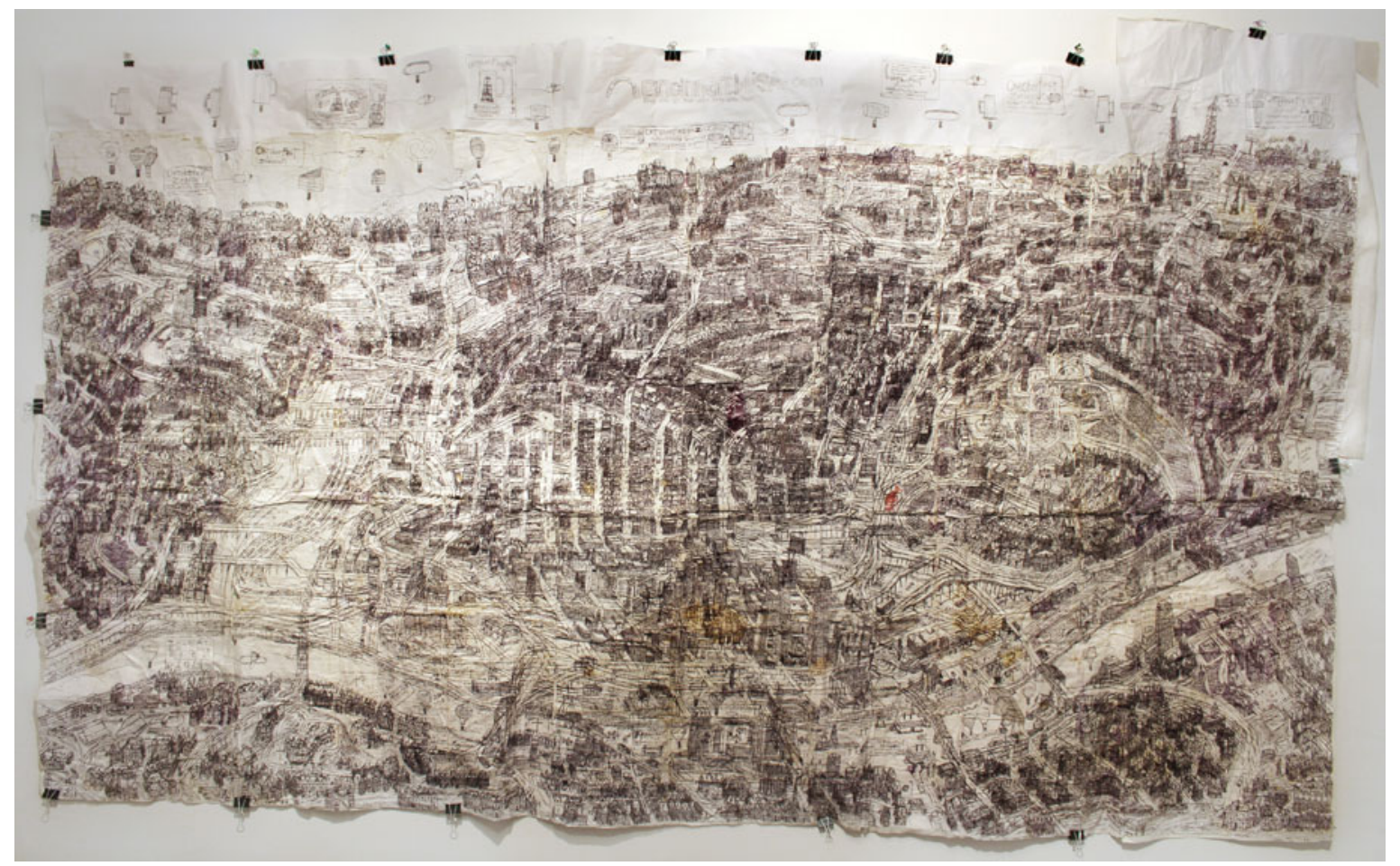

Fig. 1. Map, Cincinnati, OH.

Address for correspondence: 438 W. Belden Ave. Apt. 5, Chicago, IL 60614, USA.

(E-mail: melissaannwiley@gmail.com)
Few visual artists draw on love of place for inspiration as much as Courttney Cooper, whose lifelong passion for sketching aerial depictions of Cincinnati, Ohio, began as a child playing with his Etch A Sketch and 


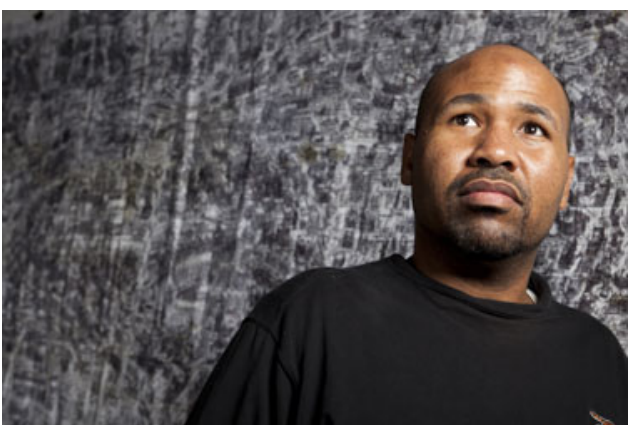

Fig. 2. A portrait of Courttney Cooper, the artist.

has continued unabated in the decades that have followed. Since 2004, he has travelled regularly from his day job at Kroger grocery store to work at Visionaries + Voices, a Cincinnati-based nonprofit supporting artists with disabilities by providing them with studio space as well as art supplies and exhibition opportunities (Arient, 2016).

Beloved in local art circles, Cooper has enjoyed seeing his art displayed at venues including the Palitz Gallery at Syracuse University, the Cincinnati Art Museum's permanent collection, the Kentucky Museum of Art, and Intuit: The Center for Intuitive and Outsider Art in Chicago (Cullen, 2017). Showcasing his work to the wider community over the years has only intensified the visceral sense of celebration characterising all his intimate portraits of home.

Those on the autism spectrum often exhibit intense focus that tends to severely restrict their interests. 'But in the hands of a visual artist,' says Rob Lentz, former executive director of Project Onward in Chicago, where he worked with dozens of artists with developmental disabilities like Cooper, 'the obsession can actually be a way to connect with other people who share the restricted interest or can appreciate the artist's expression of it. The work they create is so intense, absorbing and disorienting because their interests are so idiosyncratic and their passion for them is so deep,' (Lentz, 2017).

Although their level of detail often astonishes those who witness them, Cooper's creations are not the maps they may seem but come closer to serving as visual diaries of their maker. Viewers may be tempted to view Cooper's representations of Cincinnati as savantlike recreations, but this is not the case (Cullen, 2017). While his work borrows heavily from an acute eye for detail and a lifetime of walking his city's streets, his renderings also subvert our aspirations for objective knowledge, giving emotional experience of place its rightful due in the process.

Cooper revels in his own subjective perspective while tacitly reminding viewers they can likewise never escape their own. 'Maps are art, each with their unique distortions and representations of reality,' reflects Skip Cullen, Visionaries + Voices' exhibitions coordinator, as to why so many people respond to Cooper's work. 'Maps are synonymous in our culture with logic, measurement and factual exactness, so I think any image which can remind us there is more becomes very important,' (Cullen, 2017).

Drawn with ballpoint pen on repurposed paper taken from Kroger, the playfulness of these maps is evident. Quotes from Animal House and favourite TV series such as The Simpsons and Fish Police frequently overlay neighbourhood grids, for instance. Air balloons, flags waving from the tops of buildings and Octoberfest steins ('Its Zinzinnati Octoberfest every-

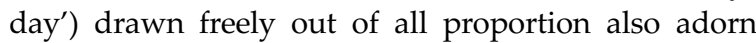
Cooper's cityscapes. 'He is always in a celebratory spirit,' says Cullen. 'I don't think it would be a stretch to say the pieces are a celebration of his city, family and friends,' (Cullen, 2017).

The works lead viewers deep into personal experience while also charting Cincinnati's shifting skyline. Other longtime residents may bemoan the changes in the city's silhouette, but Cooper displays an unrelenting enthusiasm for capturing the dynamics of a place - a city that can no more stay stagnant than he himself can as an artist. He takes advantage of any opportunity Visionaries + Voices provides him to travel to another part of the city and sketch demolition sites as well as places where new development is filling in old spaces.

As the city grows and changes, Cooper's routine and particularly his enthusiasm for the city's celebration of its German heritage - remains constant. 'He will set up a miniature Octoberfest village roughly the size of a small train display - one to two tables out of handmade cardboard and found objects,' notes Cullen. 'Once the village is set up, then he will begin taking out the drawing and working on it.' Each finished artwork, many of which show signs of autumn when Octoberfest occurs, takes Cooper approximately 6 months or so to complete. Over time, his Octoberfest villages have grown in size, both to accommodate the city's expansion as well as to allow Cooper more space to reflect on his own experiences (Cullen, 2017).

Artists like Cooper who ground maps in felt human journeys help close the distance between the world's vastness and our own limited ability to traverse it. Perhaps without being wholly conscious of his works' significance, Cooper has helped reclaim our ability to see public spaces. He has given to all those who witness his artwork their own power to view the streets - possibly the same streets they may have walked for years as fresh pathways into new experiences. 


\section{Acknowledgement}

Lentz R (2017). Interviewed by: Wiley, M (21 March 2017).

None.

\section{Financial Support}

None.

\section{Conflict of Interest}

None.

\section{References}

Arient M (2016). Interviewed by: Wiley, M (19 March 2016).

Cullen S (2017). Interviewed by: Wiley, M (8 March 2017).

\section{About the Author}

Melissa Wiley is a freelance writer and editor living in Chicago, where she volunteers with the international known Intuit: The Center for Intuitive and Outsider Art, the nonprofit organization dedicated to presenting intuitive and outsider art since its founding in 1991. She also serves as assistant editor for Sundog Lit, an online literary magazine, and is the author of Antlers in Space and Other Common Phenomena, an essay collection.

Carole Tansella, Section Editor 